\title{
Gaye-i Milliyye Gazetesinin Tıpkıbasımı Üzerine Bir Değerlendirme
}

\author{
Prof. Dr. Temuçin Faik ERTAN*
}

30 Ekim 1918'de imzalanan Mondros Mütarekesi, Osmanlı Devleti açısından bakıldığında I. Dünya Savaşı'nın sonu sayılırken, Türk ulusu açısından direnişin ve bu direniş sonrasında kurulacak olan devlet için bir başlangıç olmuştur. Mütareke'den hemen sonra başlayan ve 15 Mayıs 1919'da Yunan Ordusunun İzmir'e girmesine kadar ilerleyen işgaller karşısında, İstanbul'daki Saray ve Hükümetin teslimiyetçi bir siyasete yönelmeleri, işgal edilen ve işgal tehdidi gören bölgelerde sivil direnişi tetiklemiştir. İşgale karşı gelişen yerel örgütlenmeler, siyasal olarak müdafaa-1 hukuk cemiyetleri, askeri açısından ise Kuvayı Milliye yoluyla kendisini göstermiştir.

Söz konusu yerel nitelikli direnişler, Mustafa Kemal Paşa'nın Anadolu'ya geçmesinden sonra yayınlanan genelgeler ve toplanan kongreler sonunda birleştirilmiş ve ulusal bir nitelik kazanmıştır. Bu örgütlenme sürecinde Sivas, 1919 yılının Eylül ayından Aralık sonlarına kadar Heyet-i Temsiliye'nin merkezi olarak Kurtuluş Savaşı'nın kalbinin attığı merkez olmuş ve en hayati kararların alınmasına tanıklık etmiştir.

Ulusal Kurtuluş Savaşı'nın önderi Mustafa Kemal Paşa, Anadolu'ya geçtiği ilk günden itibaren, mücadelenin içeride ve dişarıda daha iyi anlaşılması, tanınması, tanıtılması ve doğru algılanması için yoğun bir çalışma içine girmiştir. Bir nevi halkla ilişkiler çalışmaları olarak da görülebilecek basın-yayın faaliyetleri, hemen her dönem önceliğini korumuştur. Bu bağlamda Sivas Kongresi ile birlikte yayın hayatına atılan İrade-i Milliyye Gazetesi, Heyet-i Temsiliye'nin yayın organı olmakla kalmamış, aynı zamanda Türk ulusunun bağımsızlık yolundaki çığlığının duyulmasında doğrudan rol oynamıştır.

\footnotetext{
*Ankara Üniversitesi Türk İnkılâp Tarihi Enstitüsü Müdürü..
} 
Heyet-i Temsiliye'nin Ankara'ya gelmesinden sonra, İrade-i Milliyye'nin yerini Hakimiyet-i Milliye almasına rağmen, Sivas'ta ulusal nitelikli basın-yayın faaliyetleri devam etmiştir. 1921 yılında yayın hayatına atılan Gaye-i Milliyye Gazetesi, Sivas'ın mekansal ve düşünsel öneminin devamında etkili olmuştur.

Gaye-i Milliyye, siyasi, ilmi, edebi ve iktisadi gazete başlığıyla 2 Mart29 Nisan 1337 (1921) tarihleri arasında Sivas'ta yayımlanmıştır. Maksud Azmi'nin sahibi olduğu gazetenin, mesul müdürlüğünü önce Zeki Ertuğrul, sonra da Ahmet Fa'ik yapmıştır. Tanesi 100 paraya satılan gazetenin, seneliği 300 , altı aylığ 175 , üç aylığı ise 90 kuruş olarak açıklanmıştır. Bu abonelik sürelerine bakıldığında, gazetenin uzun soluklu olarak düşünüldüğü ve en geniş kitlelere ulaşmayı hedeflediği söylenebilir.

Cumartesi ve pazartesi günleri yayımlanmayan Gaye-i Milliyye, adres olarak Sivas'ta "Hükümet Caddesi'nde Özel Daire"yi göstermiştir. Gaye-i Milliyye'nin temel sloganı " Gaye-i Milliyye istiklal ve sa'âdet-i vatandır." şeklinde ifade edilmiştir. Maksud Azmi, Mehmet Fazlullah, Sadullah, Celal Cengiz ve Deliceoğlu H. A. beyler gibi şahısların başlıca yazarları olduğu gazete, ulusal mücadelenin en çetin günlerinde Sivas'tan yükselen ulusal ses olmuştur.

Gaye-i Milliyye Gazetesi'nin tıpkıbasımı, eski Türkçe'den (Osmanlıca) yeni Türk harflerine birebir transkript edilmesiyle gerçekleştirilmiştir. Tıpkıbasım ile orijinal gazetenin ebatları da aynıdır. Gazetede yıpranma veya diğer nedenlerle okunamayan yerler “....." şeklinde boş bırakılmıştır. Özel isimler ve yazım kuralları, Osmanlı paleografyasında okunduğu şekliyle yazılmıştır.

Ulusal Kurtuluş Savaşı yıllarındaki basın-yayın organlarını eğilimleri, dağıtım şekilleri ve coğrafya açısından bir tasnife tabi tutabiliriz. Eğilim açısından Milli Mücadele Yanlısı-Milli Mücadele Karşıtı; dağıtım şekli açısından Ulusal-Yerel; coğrafi açıdan ise İstanbul basını-Anadolu basını şeklinde bir ayrışmadan bahsetmek mümkündür. Bu bağlamda Gaye-i Milliyye Gazetesi Milli Mücadele yanlısı, yerel nitelik taşıyan, Anadolu basını kapsamında bir yayın organı olarak ele alınabilir. Yerel nitelikli görünmesine karşın, Milli Mücadele'nin tümüyle ve ülkenin bütünüyle ilgili haberlere yer verilmiştir. Hatta daha da ileri gidilerek dünya ile ilgili olarak bazı olaylar da gazetenin sayfalarında yer almıştır.

Gaye-i Milliyye'nin bütün sayılarında, "Bugünün en ziyade göze çarpan haberleri" başlıklı, öncelikli haberlere yer verilmiştir. Sadece bu haberler bile gazetenin dünya görüşünü yansitabilecek örneklerdir. Bu haberleri sıralayacak olursak şöyle bir tablo karşımıza çıkmaktadır: 


\section{Sayl:}

- Teke ahâlîsi ve Trabzon Rumları, Büyük Millet Meclisi Hükûmeti'nden başka hiçbir hükümeti tanımıyoruz diyorlar.

- Yunanlılar işgâl ettikleri yurdlarımızda ahâlî-i İslâmiye'den cebr ve tazyîkle re'y ve imzâ toplamaktadırlar.

\section{Sayı:}

- Büyük Millet Meclisi'nin sene-i devriyesi münasebetiyle Mustafa Kemal Paşa Hazretleri tarafından gayet mühim bir nutuk irad edildi.

\section{Sayı :}

- Amerika-İngiltere arası açılıyor.

- Bekir Sâmî Bey konferansda mühim müdâfa'âtta bulunmuş.

- Rus Sovyet Meslis-i "Umûmîsi bir martta ictimâ" etdi. Lenin Türkiye lehinde gâyet sitâyişkâr-âne bir lisân kullanıyor.

\section{Sayı:}

- Adana'da Fransız mezâlimi gitdikce çoğalıyor.

- İtalya Hâriciye Nâzırı Kont İskorça ehimize gâyet mühim beyânâtda bulundu.

- Tan Gazetesi "Şark Mu'âhedesinin Ta'dîli” ser levhasıyla mühim bir makâle neşr ediyor.

\section{Sayı:}

- Bekir Sâmî Bey İngiliz gazetelerine pek mühim beyânâtda bulundu. Avrupa gazeteleri lehimizde gâyet müs'a'id cereyânlar var.

- İstanbul gazeteleri Anadolu hakkında sitâyişkâr-âne bir lisânla kullanarak hey'et-i murahhasamızı bu muvaffakiyetlerinden dolayı tebrîk ediyor. 


\section{Sayı:}

- Samsun ahâlî-i Hristiyaniyesi Düvel-i İtilâfiyeye terk-i iftirâkına kat'iyyen razı olmadıklarını bildirdiler.

- Amerika Avrupa işlerine karışmağa başladı.

- Hindistan'da galeyân giddikçe çoğalıyor.

\section{Sayı:}

- Yunanistan Trakya ve İzmir'de beyne'l-milel komisyonun tahkîkâtını kabul etmiyor. İngiliz mahâfil-i siyâsiyesinde bu husûsda hoşnudsuzluk eserleri görülüyor.

- Konferans Almanlara karşı ittihâzı mutasavvur tedâbir-i zecriyenin tedkîki ile meşgûl.

\section{Sayı: (Mevcut değil)}

\section{Sayı:}

- Konferansda Bekir Sâmî Beyle Doktor Nihad Reşâd Bey İzmir ve Trakya'da Yunanlıların akalliyetde kaldıklarını ve Türkler olmazsa açlarından öleceklerini vesâ'ikle isbât etdiler. Yunan başmurahhası konferansdan pek me'yûs olarak avdet ediyor.

- Şark ordumuz cum'a günü Batum'a girdi.

\section{Sayl:}

- Kürdistân 'aşâ'ir ve rü'esâsı Büyük Millet Meclisi'ne, Düvel-i I'tilâfiyeye telgraf çekerek Türk ve Kürd ekdiğerinden ayrılmaz diyor.

- Moskova ve Petrograd'da isyân çıkdığına dâ'ir İngiliz hâriciye nâzırının beyânâtını Çiçerin sûret-i kat'îyede tekzîb ediyor.

\section{Sayı:}

- Kürd "aşîret re'îsleri” arz-1 merbûtiyet eyliyor. İzmir ve Trakya'da Müslümân kardaşlarımız vahşiyâne mezâlim altında sızlanıyor. Câmi'lerimize olmadık hakâretler yapılıyor.

- Londra Konferansı hakkında mühim haberler geldi. 


\section{Sayl:}

- Almanya mes'elesi hâdd bir vaz'iyet aldı.

- Murahhaslarımızla Beriyan Londra'da görüşmüşler. Kilikya'nın tahliyesi, üserânın mübâbdelesi huûslarında i’tilâf hâsıl olmuşdur. Düvel-i i'tilâfiye tarafından Yunanlılar'a; muhasemâta devâm eyledikleri takdîrde mes'ûlliyetin kendilerine 'â'idiyeti tefhîm edildi.

\section{Sayl:}

- Cihân piyasalarında şiddetli bir buhran hükm-fermâ. Her sâ'at fi'atlarda tebdîl ve tenzil var.

- İflâslar gitdikçe artıyor.

- Müttefiklerin Almanya hudûdunda ileri harekâtı Almanların borçlarını vermeğe icbâr için imiş.

\section{Sayı:}

- Romanya 'aleyhinde Macarlar tarafından vasi' mikyasda ta'arruz tertîbâtı keşf edildi.

- Bolşevikler Lehistan'a ta'arruza başladı.

- Kilikye İ'tilâfnânemi imzâlandı.

- İtalya murahhasları 'avdet ediyor.

\section{Sayı:}

- Rus Hükûmetiyle Muhâdenet Mu'âhedesi imzâlandı.

- Gürcistan erkânı hükûmeti İstanbul'a kaçıyor.

- Mâreşâl Allenbi Mısır'da öldürülmüş Tafsîlât yarınki gazetede.

- Yunanistan İzmir'in tamâmen Yunanistan'a i’âdesini istiyor.

- Kronştad İsyânı bastırılmış.

- Yarın gece sultâni mektebinde müsâmere var. 


\section{Sayt:}

- İzmir hakkındaki konferansın kararını Yunan hey'et-i murahhasası da kabul etmedikleri için mes'elein halli Türk-Yunan murahhasları bırakmak istiyorlar

- $\mathrm{Bu}$ gece müsâmereye gitmek sûretiyle ma'ârife olan hürmetlerinizi izhâr eyleyiniz.

\section{Sayı:}

- Romanya ordusunu terhis etmeğe muvâfakat etdi.

- Türk-Yunan murahhasları ta'tîl muhâsemâtda i'tilâf etdiler.

- Mora'da muhârebe 'aleyhinde mümâyişler yapıyorlar.

- Afganistan Hükûmetiyle mu'âhede' akd edildi.

\section{Sayl:}

- Kism-1 mahsûsumuzda Rusya ile 'akd edilen "Muhâdenet Mu'âhedesi”nin hülâsasını okuyunuz.

- Gürcistan'dan İstanbul'a binlerce Ermeni muhâciri kaçıyor.

- Afganistan Hükûmetiyle "akd edilen on mâddeniz bu'âhede muc"ibince ittifâk 'akd edildi.

\section{Sayı:}

- Kral Kostantin bir beyân-nâme yazarak üç sınıf askeri silâh altına da'vet ediyor.

- Merzifon Amerikan Mektebi Rumların Pontus emellerine merkez-i fesâd olduğu keşf edilerek kapatıldı.

- Müdâfa'a-i Milliye Vekîli Fevzî Pâşâ Yunan ta'arruzu hakkında izâhât verdi.

\section{Sayı:}

- Yunan ta'arruzları kahraman kıta'âtımız karşısında sendelemeğe başladı. 
- İtalya başvekili “Türkiye’yi müstakil görmek istiyorum” diyor.

- Irak'da İngilizlere karşı ahâlînin husûmeti kesb-i şiddet eylemektedir.

- Yunan mahâfill-i siyâsiyesinde ye's ve nevmîd başladı.

\section{Sayt:}

- İstanbul Yunan ta'arruzunu protesto etdi. İkdâm bu; İstanbul'un Anadolu'ya âsî tanımadığına delîldir diyor.

- Garb Cebhemiz'de düşmanın en büyük ta'arruzu 'avn-i Hakk'la kırıldı. Kahraman kıta'âtımız düşman savletlerine şecî'âne göğüs germekdedir.

\section{Sayl:}

- 'Avn-i Hakk'la 'Uşâk meydân Muhârebesi'ni kazandık.

- Çin’de şiddetli hareket-i arzlar net^cesinde iki yüz elli bin kışi telef olmuşdur.

- Tevfik Paşa kâbînesinin isti’fâ etdirileceği tahmîn ediliyor.

\section{Sayl:}

- Batum'da bulunan Sovyet Hükûmeti grub kumandanı Çoruh mıntıkası kumandanımıza bir bayrak hediye eyledi. Makedonya'da Türk ve Bulgar çeteleri müttehiden icrâ-yı fa'âliyet ediyorlar.

- Japon kıta'âtı Sbiiryâyı tahliye edecek. Yunan ta'aruzları 'akîm kaldı.

\section{Sayı:}

- Kahraman ordumuzun muzafferiyeti her tarafda tes'îd edilmektedir. Yunan Erkân-1 Harbiyesi dört günden beri teblîg-i ersmî neşr etmiyor.

- İstanbul Türk matbû'âtı millî ordunun muzaffer olacağından emin. 
24. Sayı:

- Müdâfa'a-i Milliye Vekîli Birinci Ferîk Fevzî Pâşâ Hazretelri meclis-i millîde mühim beyânâtda bulundu. Meclisde fevkü'l-'âde alkışlandı.

- Mağlûb düşman, kahraman kıta'âtımız tarafından ta'kib edilmekdedir.

\section{Sayı:}

- Yenişehir ve İnegöl'e kahraman kıta'âtımız girdi binlerce esîr alındı.

- Bir çok mühimmât, otomobil igtinâm edildi.

- Afyokarahisârı'nda düşman pek perîşan bir sûretde kaçıyor.

- Yunanistan'da dâhilî ‘isyânlar başladı.

\section{Sayı}

- Venizelos yine seyâhatlere başladı.

- İngilizlerin müdâhalesine rağmen Fransızlar Bandırma ve İzmir hatlarıyla 'asker nakl etmiyorlar.

- Balkan Yunan münâsebâtı gerginleşiyor.

\section{Sayl:}

- Almanya'da vâsi' bir ihtilâl başladı. Saksonya Meclis-i Meb'ûsanı ber-hevâ edildi.

- Afganistan Hükûmetini temsîl etmek üzere Afganistan'dan Ankara'ya gönderilen hey'et Tiflis'den hareket etdi.

- Adana'da câmi'leri temizliyorlar.

\section{Sayl:}

- Afyonkarahisar mıntıkasında mağlûb edilen düşman şiddetle ta'kîb olunmaktadır. İstanbul'da Anadolu zaferi pek büyük bir tezâhürâtla alkışlandı. Birçok yerler bayraklarla donatıldı. Mağlûbiyet dolayısıyla Yunanistan'da büyük bir telaş ve me'yûsiyet var. 
29. Sayı:

- 'Uşak Cebhesinde lehimize müthiş muhârebât devâm etmekde ve düşmana küllî zâyi'ât verilmektedir. Bulgar ve Yunan harbi şâyi'âları te'yid etmekde de olduğunu bugünki ajans haber veriyor.

- Hilâl-i Ahmer'e yardım etmek hepimizin borcu olduğunu unutmayınız.

\section{Sayı:}

- Muhterem hemşehriler! Hilâl-i âhmer'e olan borcunuzu ödeyiniz. Gâziler sargı bekliyor.

- Yunanistan kâbinesi değişdi. Bunun da düşeceği söleniyor.

- İngiltere "amele harekâtı tevsi” etmektedir.

\section{Sayl:}

- Yunan vahşetlerindi son derece vardırdı Müslümân bî-günâh kardeşlerimiz bıçağı ile kesiliyor.

- Kardeşler işkenceleri unutmayınız kalbleriniz ateş intikâmıyla kavrulsun.

\section{Sayı:} başladı.

- İngiltere ve Ankara 'amele grevleri ciddi fa'âliyet göstermeye

- Yunan hükûmeti idâre-i örfiye i'lân etdi.

- Rusya Romanya hud^^uduna 'asker tahşîd ediyor.

\section{Sayl:}

- Antalyalılar büyük bir ictimâ' 'akd ederek Yunan barbarlarının dîndâşlarımıza tatbîk etdikleri mezâlim ve fecâyî'i protesto etmişlerdir.

- İran hükûmetiyle Rusya arasında bir mu'âhede imzâ edildi. 


\section{Sayı:}

- Numûne mektebinin 'İsmet Pâşâ Numûne Mektebi ismiyle tevsîm edilmesine ve bir kılınc ihdâ edilmesine 'İsmet Pâşâ Hazretleri teşekkür ediyor.

- Koçgiri isyânları tamâmen tenkîl edildi. Âsîler taraf taraf dehâlet ediyor.

- İstanbullular Hilâl-i Ahmer'e seksen bin lira verdiler.

\section{Sayl:}

- Büyük Millet Meclisi Hükûmeti'nin bizzât mukadderâtına vaz'-1 yed etdiği 23 Nîsân 336 nın, bu yevm-i sa'âdetin millî bayram olarak kabûl-i karârgîr oldu.

- Beyne'l-milel sergide Hilâl-i Ahmer ikinciliği kazandı.

\section{Sayt:}

- I'tilâf inzibâtının bil-hassa İngiliz zulm ve i'tisâfının esîri olan İstanbul halkı son muzafferiyetimiz dolayısıyla Anadolu rehâkârları hakkında pek derîn bir hiss-i hürmet ve samîmiyetle mütehasis olarak Anadolu zaferine ez-cân-1 dil du'â etmekdedirler. İstanbul kalblerine tercümân olan ba'zı parçaları İstanbul Gazetelerinden naklen gazetemize derc etdik.

\section{Sayı:}

- Yunan gazeteleri hezîmetlerini acı bir lisânla i’tirâf ediyorlar.

- Yunan Teblig-i resmîleri hakîkî zâyi'âtlarını yazıyorlar.

- İstanbul'da Anadolu gâzilere yardım on iki hey'et-i sıhhıye geliyor.

- Londra İslâm Cem'iyeti Anadolu'da İslâm kanı dökülmesini protesto ediyorlar.

\section{Sayı:}

- İngileter'de 'amele grevleri devâm ediyor.

- Romanya hudûd boylarını mıntıka-i harb i'lân etdi. 
- Taşköprü Hilâl-i Ahmer hanımları yirmi bir bir gurûş teberru' eylediler.

- Yunan Vahşetlerine Cân Tahammül Etmiyor.

39. Sayı:

- Japonya'nın İstanbul'a mümessil göndermesi Sovyetlerin şehr-i mezkûre girmesine yeni bir mâni' olmadığını yazıyor.

- Türkistan Cumhûriyetiyle Rusya arasında pek mühim esâsât karârgîr oldu.

- Trakya Müslümânları cebren asker ediliyor. 